\title{
E biomédica
}

No. 2

BOGOTA, COLOMBIA - ABRIL, 1984

$-$

VOLUMEN NO. 4

\section{Editor:}

Dr. Miguel Guzmán Urrego

\section{Editor Asociado:}

Sta. María del Carmen Pinzón R.

\section{Comité Editorial Central:}

Dr. Carlos Arturo Hernández

Dr. Luis Carlos Orozco

Sra. Magda Ruiz Salguero

Dr. Gerzain Rodríguez

Dr. Moisés Wassermán

INSTITUTO NACIONAL DE SALUD

Avenida Eldorado, Carrera 50

Apartados Nos. 80334 y 80080

Zona 6, Bogotá, D. E., Colombia, S. A.

\section{BIOMEDICA}

Biomédica es la revista del Instituto Nacional de Salud. Es una publicación trimestral, eminentemente científica.

Está amparada por la Resolución No. 003768 de 1981, emanada del Ministerio de Gobierno.

Ninguna publicación, nacional o foránea, podrá reproducir o traducir, sus artículos o sus resúmenes, sin previa autorización escrita del editor.

$\mathrm{Ni}$ la revista, ni el Instituto asumen responsabilidad alguna por los puntos de vista expresados por los autores.

La revista no publicará ningún tipo de propaganda comercial. Los nombres de equipos, materiales y productos manufacturados que eventualmente puedan mencionarse, no implican recomendación o propaganda para su uso y solo se mencionarán como identificación genérica.

\section{COMITE EDITORIAL REGIONAL}

\section{Dr. César Arango}

Departamento de Medicina Interna Universidad del Valle Cali

\section{Dr. Alberto Alzate}

Departamento de Microbiología Universidad del Valle

Cali

Dr. Antonio D' Allessandro

Tulane Medical Center

Department Tropical Medicine

New Orleans

USA

Dr. David Bersh

División de Salud

Comité de Cafeteros del Quindío

Armenia

\section{Dr. Pelayo Correa}

Latin American Pathology Foundation New Orleans

USA

Dr. Federico Díaz

Dpto. Microbiología y Parasitología Universidad de Antioquia Medellin

Dr. Antonio Iglesias

Departamento de Medicina Interna Universidad del Norte Barranquilla

\section{Dr. Jorge Raad}

Servicio Seccional de Salud de Caldas Manizales

Dr. Gerardo Ramírez

Departamento de Microbiología Universidad Industrial de Santander Bucaramanga

Dr. Carlos Restrepo

Armes Forces Institute of Pathology Washington

USA

Dra. Helena Espinosa de Restrepo Oficina Sanitaria Panamericana Washington

USA

Dr. Hernán Torres

Departamento de Medicina Interna Hospital Central Militar Bogotá

Dr. Gabriel Toro

Instituto Nacional de Salud Bogotá

Dr. Hernando Sarasti

Centro Médico de Los Andes Bogotá

Dr. Jaime Saravia

Departamento de Medicina Interna Hospital San Juan de Dios Bogotá 


\section{EDITORIAL}

Los grandes acontecimientos que se precipitaron en el campo de la bacteriologla a fines del siglo pasado y principios del actual, protagonizados por Louis Pasteur en Francia y Robert Koch en Alemania, como arcos torales de un movimiento, a cuyo rededor se congregó una pléyade de investigadores cuyo trabajo legó a la medicina y al género humano descubrimientos que transformaron su futuro, nos obliga, en las postrimerlas de nuestro siglo a recordar sus hallazgos y a sus protagonistas. El mundo de la medicina, usualmente es agradecido con sus prohombres, los recuerda con veneración y respeto; es asi como en 1982 se celebró dignamente el centenario del descubrimiento del "Bacilo de Koch"; en 1983 sin embargo, casi nadie recordó el centenario del transcendental descubrimiento de Elia Metchnikof, hecho en la isla Italiana de Sicilia y en el cual la Moderna Inmunología reconoce el más fundamental y eficiente mecanismo de la defensa inespecifica: la fagocitosis. 1984 expira y ninguna publicación cientifica del orbe ha recordado los 100 años del hallazgo de Hans Cristian Joachim Gram. Este patólogo Danés, asociado de Carl Friedlander en el hospital municipal de Berlín, descubrí accidentalmente el procedimiento más simple pero más desconcertante en los estudios bacteriológicos: la coloración de Gram. Desde su descubrimiento hasta nuestros días la coloración de Gram básicamente es la misma y se utiliza desde entonces ininterrumpidamente minuto a minuto; puede afirmarse, sin lugar a equivocación, que en todo momento del recorrer del tiempo, en algún lugar del mundo, se está realizando una coloración de Gram y que de ella depende la definición de un diagnóstico y el planteamiento de una estrategia terapéutica. Lo desconcertante de esta coloración es que define caracter/sticas biológicas de tal naturaleza que permite dividir las Bacterias en Gram positivas y Gram neyativas y que ni los grandes avances en el campo de la moderna biología molecular han logrado explicar el misterio químico que encierra esta coloración, hechos que, posiblemente, Gram no sospechó siquiera cuando dió a conocer el hallazgo en su trabajo "Uber die isolirte Farbung der Schizomyceten in Schnitt und Trockenpraparaten. Fortschr. Med. 1884; 2: 185-189" publicado hace exactamente 100 años. Al recordar este acontecimiento queríamos hacer un pequeño homenaje a su descubridor; pero, quizás, el mejor homenaje y reconocimiento que podemos hacer a Hans Gram sea el de realizar correctamente su procedimiento de coloración cada vez que lo necesitemos en nuestro diario trabajo. 